\title{
Chapter 7 \\ Agency, Time and Morality: An Argument from Social and Economic Anthropology
}

\author{
Paul Clough
}

\begin{abstract}
This paper reflects on the ways in which the concepts of agency, time, and morality can be linked together. It does so by considering how the kind of thinking which goes on in social anthropology and economic anthropology can contribute to our understanding of 'agency'. It then relates the discussion of agency to the concepts of time and morality. The mode of reasoning in social anthropology can be described as cyclical: social theory generates general questions that can be asked of a human society in particular times and places. Those questions stimulate empirical investigation, which results in a descriptive analysis of human social reality - known in social anthropology as ethnography. In turn, ethnography often challenges existing paradigms in social theory, because it throws up puzzles about human social interaction that can only be resolved by revising existing theory. Thus, there is a cycle in which theory stimulates ethnography, which throws up puzzles that can only be resolved by revising or changing theory. The same cycle can be discerned in economic anthropology, that sub-branch of social anthropology which understands 'economy' as a holistic social process interweaving production, exchange, and consumption (Narotzky 1997). The ethnography of micro-economic reality has provided rich evidence about human decision-making that can be used to address general theoretical questions. From its origin in studies of gift exchange (eg., Malinowski 1922) to contemporary studies of money and debt (eg., Graeber 2011), economic anthropology, like its parent discipline, has been preoccupied with theoretical questions like the tension between 'agency' and 'structure', 'individual' and 'society'.
\end{abstract}

\footnotetext{
P. Clough (deceased)

University of Malta, Msida, Malta

e-mail: paul.clough@um.edu.mt
} 


\subsection{Agency in Social Anthropology}

In a lucid short essay on the history of agency in anthropological theory, Nigel Rapport shows how ideas of agency have emerged from debates over the connection between individuals and social structure. These debates explored the nature of individual consciousness and its freedom from external determination. He defines agency as the 'capability... to be the source and originator of acts' (Rapport and Overing 2007: 3). Discussions go back at least as far as the classic differences between Durkheim and Weber. Durkheim's account of human action focused on the norms whereby choices are guided, and those structures in which norms are formed. Leaving little or no room for self-creation, Durkheim's theory contrasted strongly with that of Weber, in which the distinctively human aspect of action consists of the various features of 'rationality' - consciousness, reflection, intention, purpose, meaning. The subsequent literature has tried to overcome the opposition between Durkheim and Weber, by exploring the limits on the individual's capacity to act independently of structural constraints. In Rapport's view, all attempts have ended up privileging either structure or agency (Rapport and Overing 2007: 4).

The most influential recent attempt in anthropology to resolve the opposition between structure and agency has been Pierre Bourdieu's theory of practice (Bourdieu 1977, 1980). For Bourdieu, most consciousness is habitual. The body acts as a mnemonic device for communicating pre-existing collective codes of gender, normalcy, propriety, and domination. Thus, children encode the collective culture in their bodies through early training. Perhaps most strikingly, Bourdieu argues that competency in the different kinds of social interaction operates by individuals not thinking about how they act. Hence his key concept of habitus - 'the system of durable dispositions, predisposed to act as ... principles [that] generate ... practices and representations ... without presupposing a conscious aiming at ends' (Bourdieu [1980] 1990: 53, emphasis added). In his various precise ethnographic analyses, the room for individual manoeuvre is strictly limited by prevailing dispositions and practices. Despite Bourdieu's continuous claims to have produced a unique synthesis from the analytical opposites of structure and agency, none is detectable (Clough 2016: 202-204).

There have been notable efforts in social anthropology to outline theories that do stress the importance of agency. For example, Gregory Bateson emphasized individual creativity in generating social change (Bateson 1973). Kenelm Burridge's outline of the process whereby idiosyncratic, 'heroic' individuals persuade others, or get copied by others, demonstrates how 'eccentrics' inaugurate patterns of action that eventually become the new norm (Burridge 1979). However, in this essay I will concentrate on the arguments of Terry Evens in his 2008 volume, Anthropology as Ethics, because he ranges so widely across philosophy and social theory. Evens links agency to intention and to moral responsibility. He stresses as well the need to allow room for the unprecedented, for the act of creative imagination (Evens 2008: 
116). For Evens, a full description of the attributes of human agency entails the idea of 'self-conduction', which in turn implies the activity of genuine choice. Furthermore, reflection by the self on the self contains the awareness of a tension between the self and its surroundings, and equally, between self-interest and the demands of others. Awareness of this tension between the self and others includes belief in a personal responsibility to resolve that tension. Thus, the awareness of responsibility generates awareness of the reality of self-change (Evens 2008: 128130). I contrast Bourdieu's weak idea of agency as limited, structured change in a social system, with Evens' strong concept of agency as self-conduction in responsibility to others.

\subsection{The Argument}

Through my ethnography of one farmer-trader in West Africa, I will argue that this man's short-term economic decision-making and long-term planning implied the operation of a particular kind of agency. His decision-making involved imagination - the ability to visualize a future different from his present. The practical application of imagination entailed the qualities of intentionality and purpose, and the ability to plan for the imagined future. Furthermore, in the very framing of the goals used in his planning, he had to make choices in the ethical dilemma between expenditure on self and expenditure on family, kin, or clients. Thus, my argument favours 'strong' agency as self-conduction (Evens 2008) over 'weak' agency as the ability to slightly alter existing structures (Bourdieu 1977, 1990). Moreover, agency implicates time, because the very meaning of agency shifts as the analytical focus changes from the 'short-term' to the 'long-term'. If, in a 'short term', the question often asked with regard to agency is whether individuals can act differently than they do at particular points in time and space, the more appropriate question in a 'long term' is whether individuals can strive over time to act differently in the future than they do in the present - can install new goals, or even change some of their habits, over a period that is open to the future. Equally, reference to the long-term dimension of agency implicates morality. Here I draw on Levinas's philosophy of ethics as the inexhaustible or unending responsibility of the self to the other (in Levinas's language, the 'infinite' responsibility of Self to Other). Levinas exposes the tension between self-interest and other-regard. Awareness of tension between the demands of the self and the demands of the other includes belief in personal responsibility for the resolution of that tension. Thus, the awareness of responsibility - ethics - generates awareness of the reality of self-change over a long term (Evens 2008: 128 130). In summary, where a person persists with a particular intention, then consistency of purpose can lead to self-change over the trajectory of a life. 


\subsection{An Ethnography of Economic Action}

These various dimensions of agency can be seen in my ethnography of an individual farmer-trader among the Muslim Hausa of northern Nigeria, West Africa, to which I now turn. My research on this trader, whom I will call Abdulkadiri, was part of broader fieldwork on the relations of production and exchange in one village of Hausaland in northern Nigeria; and equally, on the trading networks for agricultural products that linked my village to other economic regions of Nigeria. Both the economic and cultural contexts of research are crucial, because they enable me to posit connections between the nature of agency and the real nature of global markets at the end of this essay. With regard to the economic context, the region where I did my research has long had a highly commercialized rural economy. By the time that I began fieldwork in Marmara village in 1976, the process of commodification had extended from products to land and finally to labour power. In Marmara, while half of all farmland had been inherited by the users, half had been acquired primarily by purchase or by borrowing the land in return for a money loan of its market value. Moreover, a half of farmland was farmed by household heads who combined family labour with hired labour. The top fifth of landowners combined farming with trading in various lines, using the profits from trade to invest in farmland and hired labour. Hence I use the term 'farmer-traders' for the social stratum of which Abdulkadiri formed a part. With regard to the cultural context, Hausa rural society was piously Muslim, and polygyny was the norm: the majority of family heads had from two to four wives. The marriage system accords wives an important degree of autonomy. Divorce is easy. Most men and women have been through several marriages.

In the complex ethnic composition of Hausa society, Abdulkadiri's ethnic background was actually Fulani, his original language - an ethnicity particular to pastoralists throughout West Africa - though he had migrated to the Hausa village of Marmara as a result of acute land scarcity in his home region. In his new home, he combined farming with trading in livestock, due to his close relationships with Fulani pastoral kinsmen who owned herds of cattle. This ethnography analyses 1 year of accumulation in Adulkadiri's life.

At the beginning of the year, in January 1978, he faced the need to make crucial decisions. He was the leader of a large family farming enterprise that included his two sons and two of his younger brothers. He combined trading in grains with trade in livestock. And he had 1600 Naira of personal savings - no mean sum in the currency of the time - which he looked upon as his working capital. But he had little land and only one wife. By the end of that year, in December 1978, Kadiri had invested all of his savings in farmland, which he had increased from 6 to over 20 acres. By combining his family work force with large amounts of hired labour, he used the additional farmland to more than quadruple his output of grains. He used part of his savings to contract successful marriages for his first son and for his unmarried brother. And he managed to marry first one, and after divorce, another woman who thus became his second wife. Over the year, Abulkadiri had successfully engaged in the accumulation of capital - investing profits from previous trade 
and production in the increased control of land and hired labour. But moreover, he had accomplished the prestigious cultural transition from a monogamous to a polygynous family head. It was - by any local measure - an astonishing transformation. How had he pulled it off?

In the course of my fieldwork, I very gradually learnt more about Abulkadiri from his occasional statements made in the midst of work. What follows is thus my analytical reconstruction based partly on his observed actions, and partly on his discourse. Years before, when he had first emigrated to Marmara, his intention had always been to eventually return to his home region to 'embrace' his parents. But they had died, leaving him without a compelling reason to return. Moreover, though his mother's family were well-connected to the hereditary rulers, his father had left very little farmland and few cattle. Thus, he weighed the absence of reasons to return against the opportunities in Marmara. By the beginning of 1978, he had come to the decision to remain in the economic region of southern Katsina, to abandon trading in livestock, and to focus his energies on agricultural production and trading. The timing was pushed because his eldest son and younger brother had reached maturity and needed to be married. In Hausa culture, the institution of family farming (called gandu) is based on a reciprocal exchange: sons and other working kinsmen receive from the household head the bridewealth needed for marriage, and food for themselves, their wives, and offspring, in return for their farm labour during the 'rainy' season and help with the household head's off-farm occupation during the 'dry' season. Hence, Kadiri's decision to abandon his residual traces of pastoral Fulani identity entailed large family responsibilities in his new focus, Hausa farming. I could see that this change in economic identity was accompanied by a certain change in his cultural identity. At the start of the year he could sometimes be seen in the customary Fulani dress, whereas by the year's end he was only wearing the Hausa robe and cap. This is not to deny that he retained close links with his Fulani kinsmen having herds of cattle. They kept for him his few remaining cattle, and being wealthy in terms of livestock, were a source of loans in emergencies (Clough 2014:274-326, 2016: 201-207).

Kadiri could not expand his landholding without finding the funds to hire the labour needed to farm it. In his trading he bought grains from local farmers for sale at a distant weekly marketplace where prices fluctuated at a much higher level than in Marmara. He continually emphasized to me that the weekly profits derived from the relatively large scale of his trading were necessary to pay for agricultural labour and other inputs. At the same time, since he had sunk his own savings into farmland and family marriages, he became increasingly dependent during the year on loans to finance his farming. Essentially, he was immersed in social relations of credit that were as important as the institution of family farming. These relations were of two kinds - patronage and trading friendship. His patron was a much wealthier trader in the same line, crop trading, who loaned him money for trade in return for Kadiri's long-term services in finding the patron new areas of supply, and selling his patron's traded grain in distant markets. His 'trading friends' (in Hausa, abokanan ciniki) were men in other lines of trade, with incomes much closer to that of Kadiri, whose marketing had different periodicities than Kadiri's crop trading. They were thus in a 
position to loan him money at times when they had realized their own commercial proceeds.

All trading loans were without interest in rural Hausa society. This had less to do with the Islamic ban on usury than it had to do with the fact that all traders were involved in such tangled and variable claims for assistance from diverse kinsmen and friends, that they could not guarantee the regular money growth necessary for stable rates of interest to settle. Here, too, as in farming, economy depended on an ethic of reciprocity. As a trader sought to obtain loans, he found himself under pressure to give them. He knew, in borrowing, that part of the credit would be loaned out again. In the local circle of traders, potential borrowers were not only being assessed for their honesty, but equally, for their 'character' (in Hausa, hali). A person with 'character' had many men from whom he attracted credit. 'Character' in Hausa incorporates the ideas of redistribution and reciprocal justice. Since the success of most traders depended on the willingness of others to loan them commercial funds, reciprocal justice required that they lend to others still struggling to succeed.

Given the demands of kinsfolk and poorer traders on his funds, it may seem surprising that Abdulkadiri was able to achieve any capital accumulation at all. His singular feat was to borrow more from the circle of patrons and trading friends than he loaned out to others. Secondly, he was able during that year to convert many short-term loans into medium-term credit. He was even able to transform the medium-term loan from his patron into a long-term loan. In these ways he generated working capital for farming in the short term.

This summary gives a more seamless sense of the logic of the rural economy that is true of the human reality. Farmer-traders are managers of multi-purpose family enterprises. In consequence, the boundaries between domestic and productive expenditure are blurred. So I turn briefly to his discourse. Over the year, he was continually praising to me the beauty of women at the distant weekly marketplace where he sold his produce. It is from there that he found the two women whom he sought for marriage. In order to ensure that the second lady remained in his household, his mind fastened on a dramatic scheme - to completely rebuild his compound in order to better house, not only his two wives, but also those of his son and younger brother. The building took time, the result impressed the whole village. To finance the construction, he converted one of his largest trading loans into building money, and as far as I could tell, was only able to eventually repay that loan by tapping the funds of distant pastoral kinsmen. We have here a whole man, endowed with an aesthetic and with desires, who sought emotional security from the company of wives and friends. Reviewing the entire year, he actually spent more on household marriages and building than his considerable expenditure on farms and farming. It was larger, too, than his weekly investment in trading. He offered a revealing summary of his recent past: 'For four years, I have not postponed marriages in my house - for myself, for my son, and for my brother. If not for this, I would have gone east [ie., to Mecca, on the Muslim pilgrimage]!' Note that he did not say, 'I would have had more money to buy farms or hire labourers.' Expenditure on farmland and hired labour were embedded in the expansion of his household and the reciprocal obligations of patronage and trading friendship in a Muslim circle of traders. 


\subsection{Theoretical Implications of Ethnography for a Theory of Agency}

Can we generalize from the specificity of micro-ethnography to philosophical or economic theory? Does a micro-study have implications for our understanding of agency? More particularly, how can meaning, purpose, intention, or self-reflection in the consciousness of the main character here - and, moreover, the changes in these - be seen to interconnect with the sequence of his actions over the period studied? I begin by asking whether a structural analysis of 'practices' in the manner of Pierre Bourdieu - 'skilled performances' based on indigenous practical knowledge in particular socio-economic niches - can explain Abdulkadiri's decision-making. It must be admitted that a structural analysis in the style of Bourdieu, based on the material necessity of certain actions in a particular economic niche, does indeed explain certain contours of his action over time. Having come from a pastoral family with limited livestock, Abdulkadiri almost inevitably gravitated from cattle herding to cattle trading. At the same time, he gradually realized that an expansion in his material income and social status required a certain oblique movement from being a trader focusing on cattle to being a trader focused on farming and agricultural trade. Analyzed thus, his change from a Fulani pastoral to a Hausa farming identity was certainly predictable.

Nevertheless, what a structural analysis cannot do is explain three elements of his consciousness. First, the unpredictability of his search for beauty. Being a man of middle age searching for women of similar age, material necessity cannot explain his search for a second wife. Moreover, a structural analysis does not construct a satisfying mental picture of his contrary urge to extravagance, as when he threw the loan of a major trading friend into house building rather than farming or trade. Secondly, his capacity to dream of a future different from his past or present. Put differently, while Bourdieu's structuralism can explain how a conscious being responds to the material pressures facing him, it cannot explain the existence of a dreaming, imaginative being in the first place. Thirdly, his sense of a disjunction between dream and reality, between present planning and its future realization, between a relatively certain today and a merely possible tomorrow. Thus, Abdulkadiri was aware of being caught between and among:

The claims from his wives, junior relatives and other close kin.

The claims from the Muslim trading community to which he belonged.

The pressures of personal desire in a polygynous context.

Such a being, being 'between', is somehow aware that he is distinct from the present spheres he seeks to manage, is disjunct from the future that he tries to turn into a reality. Human action is the putting into physical effect of wishes and dreams. Human action is a process of self-change that sometimes, as in this case, involves self-expansion.

In a sense, Kadiri was turning himself into a cause that initiates effects. Thus, he became by his actions a part of the 'structure' that constrains, or puts pressure on, 
other people, and which they in turn take into account when they initiate actions. In other words, the structure is mobile. It is continuously changing because it is full of initiatory individual actions. In contrast to Bourdieu, who claimed to have transcended the analytical opposition between structure and agency, my reflections on this one farmer-trader suggest, not some synthesis, but rather a re-worded solution in favour of agency. This is not weak agency in Bourdieu's sense of 'social change', whereby in any society one action induces an array of consequent actions that can be specified predictively given adequate knowledge. Rather, it is strong agency, what Terry Evens calls 'self-conduction' (Evens 2008: 114). Self-conduction by numerous inter-actors generates a continuously changing structure - either slowly or rapidly. 'Structure' is the assemblage of interacting actions, where by 'action' is meant the human translation of dreams and wishes into a previously non-existent reality. Since structural fixity is a chimera, it makes no sense to analytically counterpose structure and agency in the first place. 'Structure' as the assemblage of interacting actions is shot through with agency and hence mobile.

Lastly, what is highlighted by the attention given to 'planning' in the actions of Abdulkadiri, is the analytical distinction between short-term and long-term in our understanding of agency. In the short-term, the internal compulsions to act in one way rather than another - prior convictions, fixed views, strong feelings, vivid memories - combine with the external constraints of political power and economic risk to limit the subject's possibility of choice. Therefore, if 'time' is glossed as a sequence of discrete 'points', then each point becomes a short-term in which internal compulsions and external constraints shape the consciousness and actions of the subject. Where, however, time is construed as a duration of indeterminate length, open to the future, then our perspective changes. We start to invoke different kinds of verb in our reflection - 'trying', 'attempting', 'striving', 'struggling', 'searching for' (in the manner of Gilbert Ryle experimenting with different verbs for 'thought' in his Concept of Mind). Perhaps, then, what the complex and variable language of 'choosing' or 'deciding' does, is to gloss an awareness of time either as a sequence of momentary points or as a temporal stretch of indefinite duration, open to the future. If, and when, a particular intention is persistent over time, then consistency of purpose leads to gradual self-change over a long period of time. The trajectory of a person's life cannot be described without reference to his or her intentions.

Although the temporal dimension of choice is specified in variable ways, the sense of self-conduction is ineluctable. Because I am aware of being a being suspended among present pressures and future possibilities, I am conscious that the self translates possible futures into an embodied present. Pervasive in this sense of selfsuspension is the tension between self-desire and other-regard (Evens 2008: 128, 296-297). In a sentence: it is through my sense of the difference between present and future, and through my consciousness of responsibility to the other, that I become aware of the meaning of agency. 


\subsection{Implications for the Study of Global Markets}

These arguments for strong agency as a focus on individuals striving over time to change their condition or even their character, allow us to more clearly see the nature of market formation and change in different parts of the world. Markets are like any other 'structure' in my argument: they are assemblages and sub-assemblages of initiatory human interaction. As such, markets are shot through with agency, and hence mobile, constantly changing.

First, whereas a short-term perspective on markets assumes that most individuals are seeking to maximize current net satisfaction across the range of their prioritized desires, a long-term perspective opens up the possibility of a change in the very nature of their satisfactions and in individuals' hierarchies of desire. Such changes can alter the entire system of relative prices for different products and services. In the long-term, for example, changes in the consciousness of gender and of gender difference increasingly inflect consumer choice. New desires can lead to the emergence of new markets.

Secondly, focus on the intrinsically moral nature of agency enables us to shift attention from individual to collectively shared aspects of morality. I refer to the way in which social movements mobilize the collective force of their members to change public understandings of human obligation. Examples include the voluntary embargo on purchasing products from racist regimes, or the efforts by environmental movements to alter the consumer preferences of their members worldwide.

Thirdly, my Hausa micro-study points to a very particular structure in global markets - their cultural structure. The very different ways in which people in different parts of the world stratify their spending between social or public goods and individual private goods, demonstrate that markets are far more than the passive responses of anonymous, atomized individuals. Choices concerning what to produce or buy are made after public discussion and debate. In non-Western parts of the world, these choices are often made after community debates which can have recourse to religious beliefs, and - certainly in the case of Muslim societies - deliberation on the sacred texts of the religious group.

Fourthly, the cultural consequence over time of the intersection of different local and regional markets is not a universally shared concept of value. For example, despite a century of commercialization of the forces of production, all the evidence from my research area in West Africa reveals the continued priority given to household expansion through polygynous marriage, and to circles of trading friends through local systems of credit and debt, rather than to the capitalist accumulation of land and labour. As products and money circulate globally, their uses and meanings are altered in local contexts so that they express and sustain local systems of value (see also Parry and Bloch 1989).

Lastly, these diverse intersections between, on the one hand, local schemes of desire informed by political and religious movements, and, on the other, the global circulation of capital and search for profits, can only be given their full meaning if we see the entire assemblage of actions as shot through with agency in the strong 
sense. While, at any moment in time, individuals are constrained internally by fixed tastes, views and values and externally by pressures on their income, a long and open duration of time gives more scope for persistence of purpose to become a force that gradually works its way into individual decision-making.

\section{References}

Bateson, Gregory. 1973. Steps to an Ecology of Mind. London: Paladin.

Bourdieu, Pierre. 1977. Outline of a Theory of Practice. Cambridge: Cambridge University Press. . 1990 [1980]. The Logic of Practice. Trans. Richard Nice. Cambridge: Polity Press.

Burridge, Kenelm. 1979. Someone, No One: An Essay on Individuality. Princeton: Princeton University Press.

Clough, Paul. 2014. Morality and Economic Growth in Rural West Africa: Indigenous Accumulation in Hausaland. New York/Oxford: Berghahn Books.

. 2016. Tension, Reflection, and Agency in the Life of a Hausa Grain Trader. In Reflecting on Reflexivity: The Human Condition as an Ontological Surprise, ed. T. Evens, D. Handelman, and C. Roberts. New York/Oxford: Berghahn Books.

Evens, T.M.S. 2008. Anthropology as Ethics: Nondualism and the Conduct of Sacrifice. New York/ Oxford: Berghahn Books.

Graeber, David. 2011. Debt: The First 5,000 Years. Booklyn/London: Melville House.

Malinowski, Bonislaw. 1922. Argonauts of the Western Pacific. Prospect Heights: Waveland Press. Narotzky, Susana. 1997. New Directions in Economic Anthropology. London/Chicago: Pluto Press.

Parry, J., and M. Bloch. 1989. Money and the Morality of Exchange. Cambridge: Cambridge University Press.

Rapport, Nigel, and Joanna Overing. 2007. Social and Cultural Anthropology: The Key Concepts. London/New York: Routledge.

Ryle, G. 1949. The Concept of Mind. London: Hutchinson.

Open Access This chapter is licensed under the terms of the Creative Commons Attribution 4.0 International License (http://creativecommons.org/licenses/by/4.0/), which permits use, sharing, adaptation, distribution and reproduction in any medium or format, as long as you give appropriate credit to the original author(s) and the source, provide a link to the Creative Commons licence and indicate if changes were made.

The images or other third party material in this chapter are included in the chapter's Creative Commons licence, unless indicated otherwise in a credit line to the material. If material is not included in the chapter's Creative Commons licence and your intended use is not permitted by statutory regulation or exceeds the permitted use, you will need to obtain permission directly from the copyright holder.

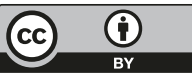

